\title{
1994 EPS LARGE FACILITIES IN PHYSICS CONFERENCE Many Challenges Lie Ahead
}

Reformating the EPS Large Facilities in Physics Conference led to a thorough appraisal in Lausanne last month of the main issues facilities must address. Maurice Jacob, who co-chaired the conference (the 5 th in the series), summarises some general impressions.

Physics relies increasingly on large facilities. They serve many external users in providing rather special, and sometimes unique, experimental possibilities. In Europe, these facilities have now taken on an international character, even those initially realized in the framework of a national programme. Their planning, construction and exploitation almost always require international discussion and often some form of international collaboration in identifying potential users; the increasing capital cost and the size of the user constituency both drive an international approach.

It is therefore natural that the EPS takes a strong interest in large facilities. EPS conferences on large facilities in physics have been held every few years. The fifth in the series, in Lausanne on 12-14 September 1994 , brought together about 170 participants (a few more than was originally planned). The conferences aim to review in parallel present and planned large facilities so that participants can grasp what is happening and being prepared in the different fields of physics. Insofar as they attract many laboratory directors and senior members of research organizations and funding agencies, the conferences also provide an excellent forum for discussions.

While physicists often tend to focus on their own field, funding agencies operate according to sum rules which increasingly impose a global view. Some fields have long-established mechanisms for selecting which large facilities should be built in the framework of an international co-operation or collaboration. Others are relatively new at this process, but even they have now to shift from a national to an international approach. Each domain of physics has therefore something, and often much, to learn from others. So although the physics questions being addressed were clearly presented, the conference dealt more with the general strategy of research than with new developments.

\section{Objectives Modernised}

The traditional role of the conference has been to review the many large facilities in the different fields of physics, particularly new facilities and those being considered for the future. In Lausanne, this was done through plenary talks, grouped according to different domains, that emphasized physics programmes as opposed to technical aspects. In particle physics, the reviews centred on present and planned developments in Europe, the United States and Asia and questions relating to data transmission, su-

percomputing and control systems. Then came nuclear physics, synchrotron radiation sources, free-electron lasers and high magnetic fields, followed by neutron sources, fusion and plasma research, and astrophysics with its ground-based installations and satellites studies. There was also a report on the detection of gravitational waves on the ground and in space and a review of large underground (underwater) facilities in physics and astrophysics. Finally, the status of ion-storage cooler rings, muon beams and laser facilities was reviewed.

Speakers kindly agreed not to focus on the facility close to their own hearts but rather to review in a global way the large facility issue in their field. And while the emphasis was naturally placed on Europe, issues were addressed in a world-wide perspective with particular attention given to Japanese programmes. The point-of-view of the users was expressed more openly than on previous conferences in the series by inviting several speakers to talk on behalf of the physics community at large and, in particular, on behalf of users. Finally, three round-table discussions each debated for about two hours the main questions of general interest to the research community. Introductory remarks by leading experts were followed by a lively and fruitful exchange of views

The conference aimed to make the participants aware of the many committees and discussion or advisory bodies that are presently heavily engaged in prospective studies of large facilities. Some of these bodies originated from the research community itself and among those with an international character one finds in particular ECFA and ICFA, in particle physics, and NuPECC and

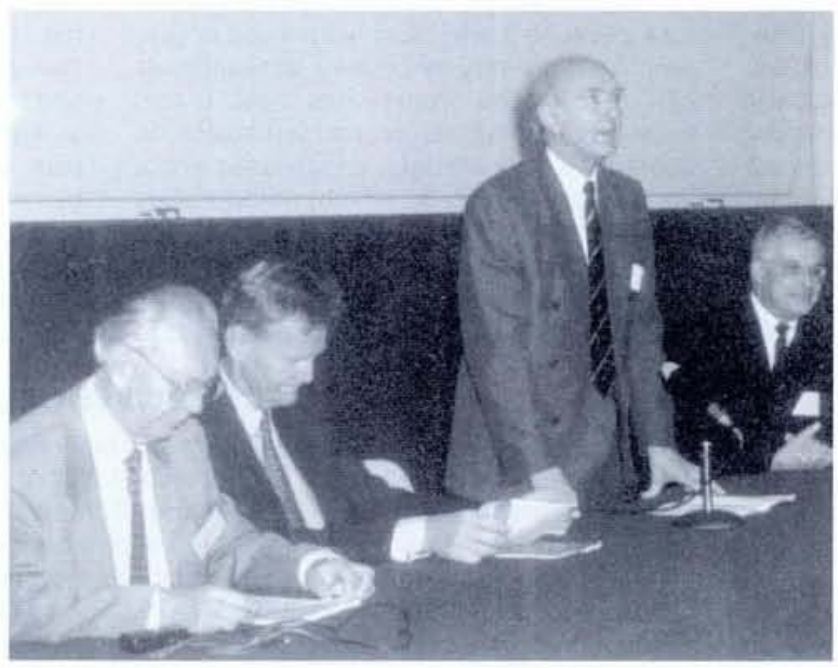

Fig. 1 - Norbert Kroo, the President of EPS, opening the 1994 Large Facilities in Physics Conference. With him are (from the left), Herwig Schopper, Pierre Ducrey (Rector of the University of Lausanne), and Maurice Jacob.
ICHIA, in nuclear physics (see page 175 for descriptions). Other bodies, including some international ones, have been set up by governments and research organizations (e.g. ESF, EUPRO, ESTA, the OECD Megascience Forum, the UNESCO-PAC, and the G7 Carnegie Group). Finally, one has the International Union of Pure and Applied Physics (IUPAP), the International Counci of Scientific Unions (ICSU) and various scientific academies at the national, European and regional (third-world) levels. Most operate as consultative bodies for governments and funding agencies, and some respond to specific requests for studies. They clearly bear witness to the present interest of government in planning so-called "heavy" science, and the need to achieve as much concertation as possible.

\section{Implications of Spreading Wider}

Whereas the emphasis was clearly on Europe, the conference presented a excellent world-wide view of the present and foreseen role of large facilities in physics. International large facilities have long been a way of life in some domains, but they account for an increasing share of activity in traditional "small" science fields such as condensed matter physics and even atomic physics, where large facilities such as synchrotron light sources and neutron sources start questioning any clear dichotomy between small- and large-scale science. While small research groups working on their own have a recent brilliant past and clearly much potential for the future, large facilities become necessary almost everywhere to address key research aspects which cannot be pursued otherwise. In some domains, detectors have already also become large facilities in their own right. In others, they remain small, but for how long? Funding agencies are having to recognize the expanding need for large facilities. At the same time, the wider demand will imply increasing co-ordination between different fields since specific projects will often have to be staggered in time, especially at the national level.

The conference not only brought forward much information but also provided some clear indication about what was best, and what had to be done. Take, for instance, the organization of large facilities: international research organizations such as CERN and the European Space Agency provide one type of model; international research laboratories such as the European Synchrotron Radiation Facility provide another. On the question of cost per user: the cost sometimes appears to be high for a large facility since the capital investment and the operating budget are combined. On the other hand, a large facility increases competitivity and diminishes redundancy and the need for many small-scale installations. But they imply travel costs. The conference effectively invited EPS to clarify with hard facts the cost of physicists in different fields. 
When the cost of a fair-sized facility was of the order of 50 MSFR or less, proponents could work at obtaining approval and funding by following specific local rules. The rules for new facilities are now very different, for in order to be competitive and to explore new ground they cost up to 500 MSFR, and sometimes much more. Assuming clear scientific needs, approval can only be envisaged if there is a sufficiently large constituency of potential users, which in Europe at least, nearly always requires international collaboration. So it is important to have concertation and advisory structures which can assess the needs and the sizes of potential user communities and formulate recommendations. The conference highlighted the increasing number of advisory bodies, and their members learnt much about each other.

Some participants from outside Europe openly expressed recognition of the

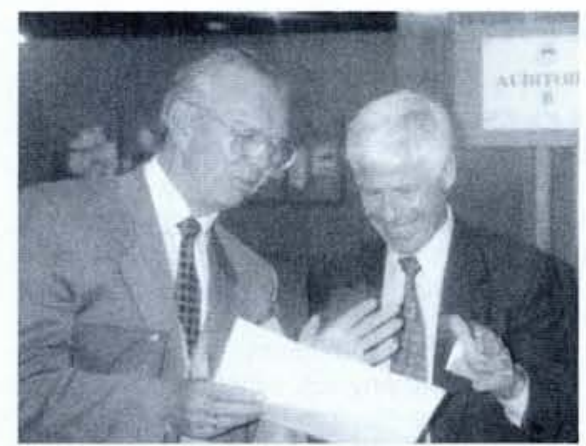

strength and the apparent health of "heavy" physics in Europe, and that this was reflected by the conference. Such strength is important because, sadly, the end of the cold war which could have resulted in increasing support for heavy science appears instead to have prompted an increasing questioning of its value. What is clear, how-

Hubert Curien opened the EPS Large Facilities in Physics Conference in Lausanne (12-14 September 1994) by describing the difficult, but not insurmountable, realities that promoters and users of facilities must face.

\section{There Should Be No Illusions}

Our reflection on the significance of facilities in physics comes at an appropriate time because the European Synchrotron Radiation Facility in Grenoble recently held its official inauguration. The source works beautifully and represents a remarkable success for our continent. We are also in the final stages of deciding upon the Large Hadron Collider (LHC) at CERN. Discussions are coming to an end; all involved understand that we need such a machine and that we need to make a rapid decision.

In discussing large facilities one should first say what they are. A quantitative definition in terms of say the part of the national science budget that is spent on a certain facility is possible. But the amount depends very much on the size of the country, so a reasonable criterion could be to say that a facility is considered as large if it needs say $0.5 \%$ of the annual science budget

But there are other - essentially qualitative - criteria. One is the need for consultation. If a facility has a significant size it will generally be discussed by various ministers within a country. There is also a need for a pluriannual programme: money is required not only for construction but also to run a facility. The problem here is that most countries have annual budgets while a facility has to have a commitment for a long period. However, this internationalisation may help to stabilise a situation as it tends to persuade governments to continue funding.

\section{Structures at All Levels}

There has been a blossoming of interest these last few years in discussing facilities. At the national level, almost all mediumsized countries now have a forum where facilities are analysed. For instance, in my country (France) a committee for large instruments looks at all instruments across several fields. This is understandable because public-sector investments in large facilities are substantial (close to $10 \%$ of GDP in most industrialised countries). In large countries such as the USA there even tends to be specific committees for given fields (e.g., the US Department of Energy's High-Energy Physics Advisory Committee). Regional bodies may exist and a good example is the European Science Foundation that initiated and piloted the discussions that led to the creation of the ESRF. Finally, some global structures have emerged. I shall mention three. The Organization for Economic Co-operation and Development (OECD) Megascience Forum started from an idea of Allan Bromley, the Scientific Adviser to a former US President. $\mathrm{He}$ thought that the OECD was a good place to promote discussions: decisions could not be taken but analysis and recommendations were possible, as in a true forum. He was confident that the OECD could handle the task because it was heavily involved in very respected country-by-country assessments of science. The Forum has held expert meetings and made recommendations in several fields. I am less enthusiastic about its plenary sessions (which unfortunately cannot be avoided) where the "rule of inverse proportionality" seems to be the case (the less one has to say, the longer it takes to say it). UNESCO has created a
Fig. 2 - Herwig Schopper, the conference chairman, with R.M. Bonnet (on the left), Director of the European Space Agency's Science Programme. In addressing the opening ceremony of the Large Facilities in Physics Conference, Professor Schopper saw the main challenges as being:

- to adjust to the fact that more and more fields in physics need facilities;

- to make the best use of resources as they are under pressure;

- to find new ways to co-ordinate as the need for more international cooperation makes political procedures more difficult.

ever, is that funds saved on large facilities will not be transferred to small-scale science, but will be lost to basic research. With such issues in mind, participants were made aware of the challenges that lie ahead, and of the sometimes very different ways they are being approached.

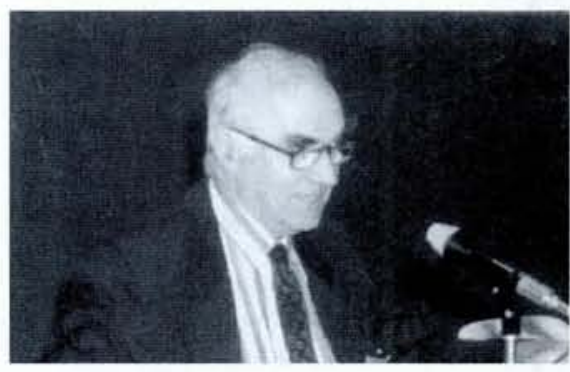

Hubert Curien

Physics Advisory Council and in the field of space activities, the coordinating body for the 1992 International Space Year has now evolved into the Space Agency Forum.

\section{Difficulties Remain}

Nonetheless, there remain certain difficulties as regards large science. We should look at the causes and come up with proposals to remedy the situation. I shall consider two fields, namely space science and particle physics. The first does not entirely concern physics, but there is much involved. There has been a dramatic change since the end of the cold war period when Europe was very much an adjunct to the US and the USSR. Few now care about the space station: no political conquests are needed and few scientists would have been involved in experiments in the station. Some scientists naturally think that with the same money one could do many other things. The problem is that one will never have the same money; if money is not spent in one field in science, there is no hope of transferring it to another. The pots simply do not

\section{ACKNOWLEDGEMENTS}

The 1994 EPS Large Facilities in Physics conference benefitted greatly from the help of Professor C. Joseph and Mrs. B. Rothen of the University of Lausanne who took charge of the local arrangements. The EPS nature of the conference was stressed by having the organizing committee composed of representatives of EPS Divisions and Interdivisional Groups. The Society also received much advice and help from The Physical Society of Japan and from The American Physical Society. Thanks to the generous support of the European Commission, the Divisions and Groups were able to sponsor several young participants; other support from various organizations was used for participants from central and eastern Europe and from the former Soviet Union. The proceedings, to be published early in 1995 by World Scientific, will include the review talks and summaries of the roundtable discussions. 